\title{
Polysemy and Semantic Extension of Lexeme "Hot"
}

\author{
Truly Almendo Pasaribu \\ ELESP - Sanata Dharma University \\ tr.almendo@gmail.com
}

\begin{abstract}
Polysemy is a well-known fact about language. This study focuses on describing the concept and the extended senses of lexeme hot found in the corpus. The data taken from the corpus show that lexeme hot contains more than one semantic representation. This study aims at finding out the prototypical meaning, the extended senses and the relation between the prototypical meaning and the extended senses. First, the paper discusses the literal meaning of hot from its componential analysis, which will be supported by the Natural Semantic Metalanguage. After elaborating the prototypical meaning of the lexeme hot, this paper elaborates the extended senses of the lexeme and the motivation grounding the various types of these senses. Finally, it analyses the relation of the literal and the extended senses of the word by drawing the semantic networks. This research elaborates 10 extended senses of the word hot found in the corpus. The prototypical meaning of the word indicates a "very high degree of temperature". It is a scale used to describe high degree of temperature. The senses of lexeme hot are mostly motivated by metaphoric extension, in which hot is used to describe a scale to measure other things. The relation of the senses enables us to draw the semantic network of the polysemy of lexeme hot.
\end{abstract}

Keywords: semantic extension, polysemy, metaphor, semantic network

\section{INTRODUCTION}

Human creativity in using language is not only seen through new creation of words, but also through various meanings represented by a single phonological form. To provide basic human needs to interact with their surroundings, language is always changing and developing. Meaning is one dynamic aspect of language. Falkum (2011: 9) mentions the various senses of the word run. Its meaning in the verb phrase run a half marathon is clearly different from the one it has in run some water, run on gasoline, run on empty, run a shop, run late, run away from responsibilities, run in the family, or run for President. This phenomenon is described as polysemy. Polysemy is described as the association of two or more related senses with a single word form. A further issue that an account of polysemy representation must address is how the relations between the polysemous senses are represented in the mental lexicon. In the cognitive linguistics tradition, the senses of the word are related to each other in a certain degree. Polysemous lexical items can be represented as a network of senses centred on a primary, prototypical sense.

Words can take on new meanings, shrinking or (more commonly) extending the domain of their reference (Finegan, 1992:95). Finegan gives example of the word dove and hawk. During the Vietnam War, the word hawk came to be used in reference to supporters of the war while dove referred to supporters of peace. The extension of these words comes from the combative nature of hawks and the symbolically peaceful role assigned to doves. The new meanings did not replace the earlier ones but gave us, in effect, new words by extending the domain of reference for old words. Like other feature of language, meaning shifts through times (Ullman, 1977: 247). This phenomenon described by Finegan (1992), the semantic shift or metaphorical extension, is motivated by metaphors. The metaphorical use of words often leads to new meanings that come to seem perfectly natural. Then a form of language with more than one related meaning is called polysemy.

Polysemy is described as the association of two or more related senses with a single word form. A further issue that an 
account of polysemy representation must address is how the relations between the polysemous senses are represented in the mental lexicon. In the cognitive linguistics tradition, the senses of the word are related to each other in a certain degree. Polysemous lexical items can be represented as a network of senses centred on a primary, prototypical sense.

Some researchers devoted themselves in studying this interesting phenomenon of polysemy. One of them is a dissertation by Ibarretxe-Antuanano (1999) who investigates cross-linguistic polysemy and metaphor over perception verbs. He compares perception verbs found in English, Basque and Spanish. Another study is conducted by Wijaya (2011) to complete his thesis entitled Polisemi pada Leksem HEAD: Tinjauan Linguistik Kognitif. This research is conducted to analyze the polysemy of lexeme HEAD. He found that there are 13 type of various senses of the lexeme HEAD.

In English, the word hot is usually used to describe a high temperature. Other words in English that describe temperature is: hot, warm, lukewarm, cool and cold. However, in daily communication, these words are not only expressed to describe temperature, which is extremely basic human experiences. We may feel hot, warm, lukewarm, or cold as a result of the temperature of air surrounding us. Usually lexemes which are extremely basic human experience have more than one semantic representation (Kovecses, 2010: 21). With this thought in mind, this study aims at finding out the prototypical meaning, the extended senses and the relation between the prototypical meaning and the extended senses. The data of the lexeme HOT found in 77 sentences taken from texts and corpus from Internet show that the word HOT contains more than one meaning. The data are limited to the single lexeme HOT, which means that the paper will exclude the idiomatic construction of the word.

The concept of hot found in the data will be analysed in three steps. First, the paper discusses the prototypical meaning of the word hot from its componential analysis, which will be supported by the Natural Semantic Metalanguage analysis of the word. After discussing the prototypical meaning, this paper will elaborate the extended senses and the motivation grounding the various types of these senses. Finally, it analyses relation of the literal word and the extended senses of the word by drawing the semantic networks of the senses.

In order to achieve this goal in mind, after this brief introduction, this paper is divided into three sections. First, it elaborates the literature framework used in this paper, which is followed by the explication of the finding and discussion. Next, in finding and discussion section, the paper discusses the prototypical meaning of the word hot from its componential and Semantic Natural Metalanguage analysis, the extended senses of the word hot as well as the motivation grounding the various types of those senses, and the relation of the literal or prototypical word and the extended senses of the word. Finally, it closes the discussion with the conclusion.

\section{LITERATURE FRAMEWORK}

Below are the discussions of related literatures which are considered suitable to be the ground of this research.

\section{Componential Analysis}

Componential analysis, also called feature analysis or contrast analysis, refers to the description of the meaning of words through structured sets of semantic features, which are given as "present", "absent" or "indifferent with reference to feature". The method thus departs from the principle of compositionality. Componential analysis is a method typical of structural semantics which analyses the structure of a word's meaning. Nida's theory is applied to identify the componential of lexeme HOT. To analyze that Nida (1975: 54) set some basic steps as follows:

1. Collecting a tentative selection of meanings which appear to be closely related.

2. Listing all the specific kinds for each of the meanings belonging to the domain.

3. Determining those components which may be true of the meanings of one or more terms. 
4. Determining the diagnostic componets applicable to each meaning.

5. Cross-checking with the data obtained by the first procedure.

6. Making a systematic description of the diagnostic features.

In analyzing the semantic components of words related to the lexeme hot, this research will use (+) symbols which means the words have certain semantic components.

\section{Polysemy and Semantic Extension}

Polysemy is a form of language that has more than one related senses. Polysemy might be caused by the semantic extension of the word. This phenomenon occurs in many languages. Polysemy can be motivated by metaphor and metonymy. Many polysemous senses are clearly related metaphorically (Cruse, 2000: 112). Here we will simply characterize metaphor as figurative usage based on resemblance. A good example of a set of readings related metaphorically is provided by position.

1. That is an uncomfortable position to sleep in.

2. This is a good position to see the procession. John has an excellent position in $\mathrm{ICl}$.
3. You've put me in an awkward position.

4. You must position yourself so she can't miss you.

These examples show that the lexeme position can be used to express various shades of meanings. The relation of the senses and their grounding motivation are two interesting things to be analyzed.

\section{Semantic Network}

A lexical item used with any frequency is almost invariably polysemous. In this sense, it has multiple, related meanings that have all been conventionalized to some degree. Among these related senses, some are more central, or prototypical or literal, than others, and some are schemas that are elaborated or instantiated by others. To some extent the senses are linked by categorizing relationships to form a network. For example, originally the noun "mail" referring to physically embodied messages delivered through a postal system, is now well established for what is also known as email, messages delivered electronically by computer. At one stage this use of mail was innovative. The lexical unit mail was invoked to designate its electronic counterpart (Langacker, 2008:224).

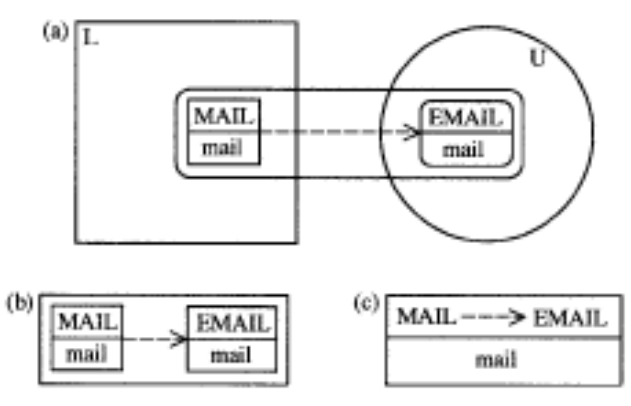

In the case of mail, the original, extended, and schematic senses are all well established and capable of being evoked as its meaning, depending on the context. They are thus related, where the heavy-line box indicates that the original meaning [MAIL] (i.e. 'hard mail') is prototypical and most easily elicited (Langacker, 2008:224). This mininetwork is part of a somewhat larger network representing the conventional semantic value of mail. 


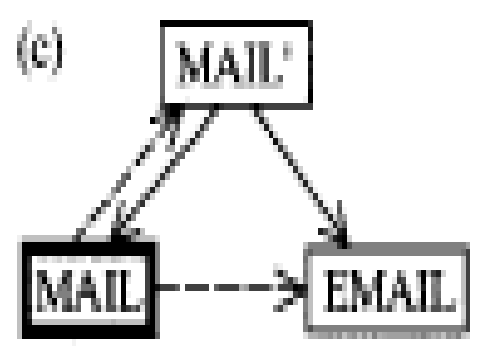

The occurrence of mail in the utterance is interpreted as manifesting the symbolic unit [MAIL/mail] even though, in the context of the usage event, it is understood as referring to electronic messages: (EMAIL/mail). This usage is now well established, so both the symbolic structure [EMAIL/mail] and its categorization by [MAIL/mail] have the status of conventional units. Since the original unit has not been lost, mail is now polysemous, having both 'hard mail' and 'email' as well-entrenched meanings. To some extent, the latter sense is still understood as an extension from the former, just as indicated in the diagram (Langacker, 2008:224).

\section{DATA COLLECTION}

This study uses a qualitativedescriptive research that focuses on the description of current language phenomenon. The method is carried out by gathering the data, analysing the data and presenting the data. The British National Corpus < http://www.natcorp.ox.ac.uk/ > gives a natural and concrete data of lexeme hot, while Longman of Contemporary English Dictionary gives ease to collect data which are not found in the corpus. Deignan (1997:153) stated that corpus analysis of meaning is bottom up not top down, that is the word should be analyzed from its forms to its senses.

\section{FINDINGS AND DISCUSSIONS}

In this section, this paper discusses the prototypical meaning of lexeme HOT from its componential and Semantic Natural Metalanguage analysis. Secondly, this paper finds the extended senses of the word hot as well as the motivation grounding the various types of those senses. After finding the various types of senses, this paper shows the relation of the prototypical lexeme and its extended senses through semantic network.

\section{The Prototypical Meaning of Lexeme Hot}

The word hot has appeared in the ancient English. The roots of Germanic hot go back to the Old English period. According to Kleparski (2007) the semantic history of the adjective is the history of the proper adjective originally expressing a well-known quality or condition of material bodies, due to a high degree of the molecular energy known as heat, the sense with which hot has been present in English since Anglo-Saxon times (Kleparski, 2007). The corpus shows that in many sentences the word hot is used to describe a very high degree of temperature. This is confirmed by Oxford Dictionary which states that hot as "having a relatively or noticeably high temperature." The word hot is often mentioned as an antonym of the word cold, but it is actually a gradual antonym. The word hot is related with other lexemes in the domain of temperature, that is warm, lukewarm, cool, cold.

Lexemes which are on the same hierarchical scale as hot are warm, luke, cool dan cold. From their usage, we can say that hot is described as having a high or higher than desirable temperature and as causing a sensation of heat or burning. The concept of warm is having or producing a comfortable and agreeable degree of heat or imparting or maintaining heat. The concept of lukewarm is neither cold nor hot. The concept of cool is a low temperature. The concept of cold can be defined as having

a low or inadequate temperature. Therefore we can compare and contrast those lexemes as shown in the table below: 


\begin{tabular}{|l|c|c|c|c|c|}
\hline \multirow{2}{*}{} & \multicolumn{5}{|c|}{ Suhu } \\
\cline { 2 - 6 } & Very high & High & Medium & Low & Very Low \\
\hline Hot & + & & & & \\
\hline Warm & & + & & & \\
\hline Luke & & & + & & \\
\hline Cool & & & & + & \\
\hline Cold & & & & & + \\
\hline
\end{tabular}

If compared with other lexemes on the same hierarchical scale, hot has a distinctive feature that is [+very high temperature]. However, componential analysis is not adequate to explain the prototypical meaning of the word hot, so this research include the semantic natural metalanguage analysis of hot elaborated by Wierzbicka (1992):

This thing is hot.

This thing is like this:

If a part of a person's body touches this thing,

This person can feel something in this part of the body because of it

Because of this, this person can know something about this thing

Because of this, this persom can think like this: "something can be like this if a short time before it was in a place where there was fire. A person can feel something bad in part of their body if this part of the body touches something when it is like this"

The use of the literal meaning of the word hot can be seen in many numbers in the corpus, this one is an example:

(1) That rice was hot when I had it so I burnt my tongue.

It is seen that the meaning of the word hot in this sentence is describing very high temperature. In the next section, this paper will elaborate the extended senses of the word hot.

\section{Extended Senses of Hot}

There are 10 extended senses of the word hot found in the corpus. Below is seen the extended senses of the word hot and the possible reason of the extension.

\section{Burning Taste}

Food that produces a strong burning taste can be described with the adjective hot.
The food is usually made of chilies, pepper, or ginger. The use of the word hot in this sense can be seen as follow:

(2) This is a dish that's spicy but not too hot.

(3) A spicy sausage, often called 'lucania', red hot 'peperoncini' and smoked hams are particularly popular.

Wierzbicka (1992) describes the literal hot in the temperature domain as:

"something can be like this if a short time before it was in a place where there was fire. A person can feel something bad in part of their body if this part of the body touches something when it is like this"

This sense of the word hot is carried by means of metaphor because both temperature and food produce a burning sensation. When talking about food, the burning sensation occurs on the taste nerves, although the tongue is not literally burned or having a very high temperature. It can be explained by the conceptual metaphor [SPICY FOOD IS HEAT].

\section{Intense Activity}

The use of the word which are classified in the domain of temperature is pervasive to describe an activity. For instance, when we use literal sense of hot, we use lexeme hot as in sentence (4) to describe things producing an uncomfortable sensation of heat.

(4) The weather is hot, so bring your umbrella.

Because temperature is close to our physical experience, we often express something else using our intimate concept of temperature. It is not difficult to find the word hot describing an activity, specifically to show that the activity is very intense. We should note how the intensifier in the description of the temperature is applied in describing an activity. For example: 
(5) The fighting became hot and heavy.

(6) He beat hot competition from Lovejoy lan McShane and Noel Edmonds, whose TV show Noel's House Party picked up a BAFTA award at the weekend.

It is interesting to notice that both fighting and argument in this case are two different activities. From the example above, we can see that $a$ hot fight or a hot argument is intense and involves a great deal of determination. Specifically we see that the conceptual metaphor in the examples [A SCALE OF COMPETITION IS A SCALE OF TEMPERATURE]. Generally, we have the extension sense of the word hot through conceptual metaphor. The two different domains are associated because temperature is extremely basic human experience. We always experience heat, cold, and warm in our daily live. We can feel warm or cold as a result of the temperature of the air that surrounds us. We often use the temperature domain metaphorically to talk about intense activity.

\section{Intense Excitement, Passion, and Enthusiasm}

The use of the word hot here is to describe a high degree of psychological traits. Like the previous meaning, the the sense of the word hot which indicates "intensity of excitement, passion and enthusiasm" is motivated by metaphor. For example:

(7) The idea had been nurtured in his hot imagination.

\footnotetext{
Although psychological traits and temperature are abstract concepts, temperature is something more familiar to our physical experience. While literally hot means very intense degree of temperature, in this case hot means very intense degree of imagination (7). One can use the word hot to describe something that is very exciting and that we want to become involved with. The ground motivating this extension is the metaphor [A SCALE OF PSYCHOLOGICAL TRAITS IS A SCALE OF TEMPERATURE]. To some extent, the sense of hot in (7) is still understood as an extension from prototypical one.
}

\section{Unusually Great Skill}

The word hot is also used to describe a person that is knowledgeable about something. It expresses positive evaluation on somebody. It is again motivated by the use of metaphor that [A SCALE OF SKILL IS A SCALE OF TEMPERATURE], as shown in this example:

(8) You should see the hot drummer who'll show you what a drum can do

(9) He scores 42 for Chicago Bulls. He's hot tonight.

Both examples above use hot to describe that someone is great at something. In the former example (8), it describes the skill of the drummer; while the later example (9) shows that a basketball player is good at playing something.

\section{Very Popular or Successful}

The lexeme hot is used to describe a very popular person or successful person. It is again motivated by metaphor. The semantic extension of this meaning is to show the degree of success or popularity.

(10) She is one of the hot young girls in school.

(11) The hot new businesses on Wall Street are constantly changing.

While literally hot means very intense degree of temperature, in this case the word hot means a very popular girl (10) and very successful businesses on Wall Street (11). People who are successful are in the higher level of the social class, and hot is prototypically a high scale of temperature. The similarity of these two domains is MORE IS UP, which leads to a more specific metaphor-[A SCALE OF SUCCESS IS A SCALE OF TEMPERATURE].

\section{Very Unpleasant or Dangerous}

The word hot is also used to describe something negative that is something very unpleasant or dangerous. The semantic extension of this meaning is to show a high degree of danger or unpleasant situation. 
(12) Yet when a scorpion rushed straight at him, he ran out of his hut to cry to a sixyear-old child outside 'There are hot beasts within!'

(13) Labour MP Miss Hilary Armstrong and the Liberal Mr Matthew Taylor have already agreed to speak, but a reply is still awaited from the Conservatives, says Mrs Robinson, who wants to put Darlington's political contenders in the hot seat with a similar local meeting.

Different from other positive evaluation of the word hot, the word is used to describe very unpleasant or even dangerous things as shown in (12) and (13). It functions as an adjective to scale the degree of danger. Example (12) shows that the adjective hot describes a dangerous animal. Like in example (13), we can use hot to describe situation that is unpleasant and difficult to deal with. If one is in hot seat, one is responsible for making important and difficult decision. The motivation for this extension can be explained by conceptual metaphor [A SCALE OF DANGER/DIFFICULT SITUATION IS A SCALE OF TEMPERATURE].

\section{Most Recent News}

The superlative in "newest" or "most recent" indicates a quantifier meaning, that is the greatest in amount or extent or degree. The word hot also shows the highest temperature in the realm of temperature. Therefore, a new extension appears, that is 'hot news means newest or most recent news'.

(14) Well if you hear any hot news from Yougoslavia, you'll let us know, won't you.

Wierzbicka (1992) defines the term hot from semantic natural metalanguage as

"something can be like this if a short time before it was in a place where there was fire." Food will have a hot temperature just after we cook it.

The key term "a short time" is applied to the field of journalism and produces meaning "newest and most recent news". Therefore, the extension of this sense is motivated by conceptual metaphor [A SCALE OF TIME IS A SCALE OF TEMPERATURE].

\section{Recently Stolen}

The word recently means in the recent past'. Recent means the immediate past or just previous to the present time. The lexeme hot is also used informally to refer to recently stolen and too easily identifiable to dispose. One can use the word hot to describe something that no one wants to deal with, often because it has been illegally obtained and is very valuable.

(15) These jewels are hot.

(16) Who would buy this hot ring you stole from the museum!

It describes goods that have been recently stolen and are therefore difficult to sell or dangerous to deal with because the police are still looking for them. It is called hot because in dealing with hot items in this sense, the person's body temperature raised and heart beat increased.

\section{Sexually Attractive or Exciting}

The word hot also indicates sexually stimulating or sexually attractive. This sense can refer to both men and women, as shown below:

(17) Just like some people will never be able to become a Hollywood actor, some people won't be able to have hot sex - so why do sex therapists say they can?

(18) I'm hot for you, baby.

Sexual attraction is considered exciting to the persons who experience it. The word hot is used to scale the degree of sexual attractiveness of the persons. Similarly to other temperature descriptors, the two terms are exponents of the metaphoric mapping 'temperature stands for sexual attraction' which is alleged to have an experiential basis in the physiological changes, such as raised body temperature and increased heartbeat, which accompany states of arousal.

\section{Very Responsive Temperament}

This sense is related to the ancient four temperaments. Choleric is associated with the element of hot and dry. In this case 
temperature stands for temperament or emotion. When people have a hot tempered trait, they get angry very quickly and easily.

(19) He is so hot-tempered and excitable, like a battle of soda water exploding.

(20) His hot temper was making it increasingly difficult for others to work with him.

When describing someone as hot-headed, we are criticizing them for acting too quickly, without thinking of the consequences.

(21) You should ignore Tom, he is a hotheaded bully like his dad.

\begin{tabular}{|c|c|c|}
\hline No & Sense & Example \\
\hline 1 & Hot means 'high degree' & $\begin{array}{l}\text { Surabaya is hotter that Malang, so you don't need to } \\
\text { bring your jacket. }\end{array}$ \\
\hline 2 & Hot means 'burning taste' & This is a dish that's spicy but not too hot. \\
\hline 3 & $\begin{array}{l}\text { Hot means 'very intense } \\
\text { activity' }\end{array}$ & The fighting became hot and heavy \\
\hline 4 & Hot means 'intense color' & The idea had been nurtured in his hot imagination \\
\hline 5 & $\begin{array}{l}\text { Hot means 'performed or } \\
\text { performing with unusually } \\
\text { great skill' }\end{array}$ & He scores 42 for Chicago Bulls. He's hot tonight. \\
\hline 6 & $\begin{array}{l}\text { Hot means 'very popular or } \\
\text { successful' }\end{array}$ & She is one of the hot young talents. \\
\hline 7 & $\begin{array}{l}\text { Hot means 'very unpleasant } \\
\text { or even dangerous' }\end{array}$ & $\begin{array}{l}\text { Yet when a scorpion rushed straight at him, he ran out of } \\
\text { his hut to cry to a six-year-old child outside 'There are hot } \\
\text { beasts within!' }\end{array}$ \\
\hline 8 & $\begin{array}{l}\text { Hot means 'newest or most } \\
\text { recent news' }\end{array}$ & $\begin{array}{l}\text { Well if you hear any hot news from Yougoslavia, you'll let } \\
\text { us know, won't you. }\end{array}$ \\
\hline 9 & Hot means 'recently stolen' & These jewels are hot. \\
\hline 10 & $\begin{array}{l}\text { Hot means 'sexually excited } \\
\text { or attracted' }\end{array}$ & She's hot alright. \\
\hline 11 & $\begin{array}{l}\text { Hot means "very responsive } \\
\text { temperament" }\end{array}$ & $\begin{array}{l}\text { He is so hot-tempered, like a battle of soda water } \\
\text { exploding. }\end{array}$ \\
\hline
\end{tabular}

This study proposes that the lexeme hot can be modelled in terms of a semantic network consisting of a central meaning and eleven distinct senses. Each distinct sense is shown in the rectangles in the network. The central sense occupies a bold rectangle, indicating its status as the literal or prototypical meaning. Evans (2006:347) studies the word over and in the study he mentions that the word over has many senses,
In this case the adjective hot in the compound noun is used to describe a very quick action. The word hot is used to scale the fast response or action. It is metonymically extended form the literal hot, as what Wierzbicka (1992) describes hot as "something can be like this if a short time before it was in a place where there was fire"

\section{Semantic Network}

This section analyses the relation of the literal or prototypical meaning and the extended senses of the word by drawing the semantic networks of the senses. A summary to the distinct senses is given in table below: 


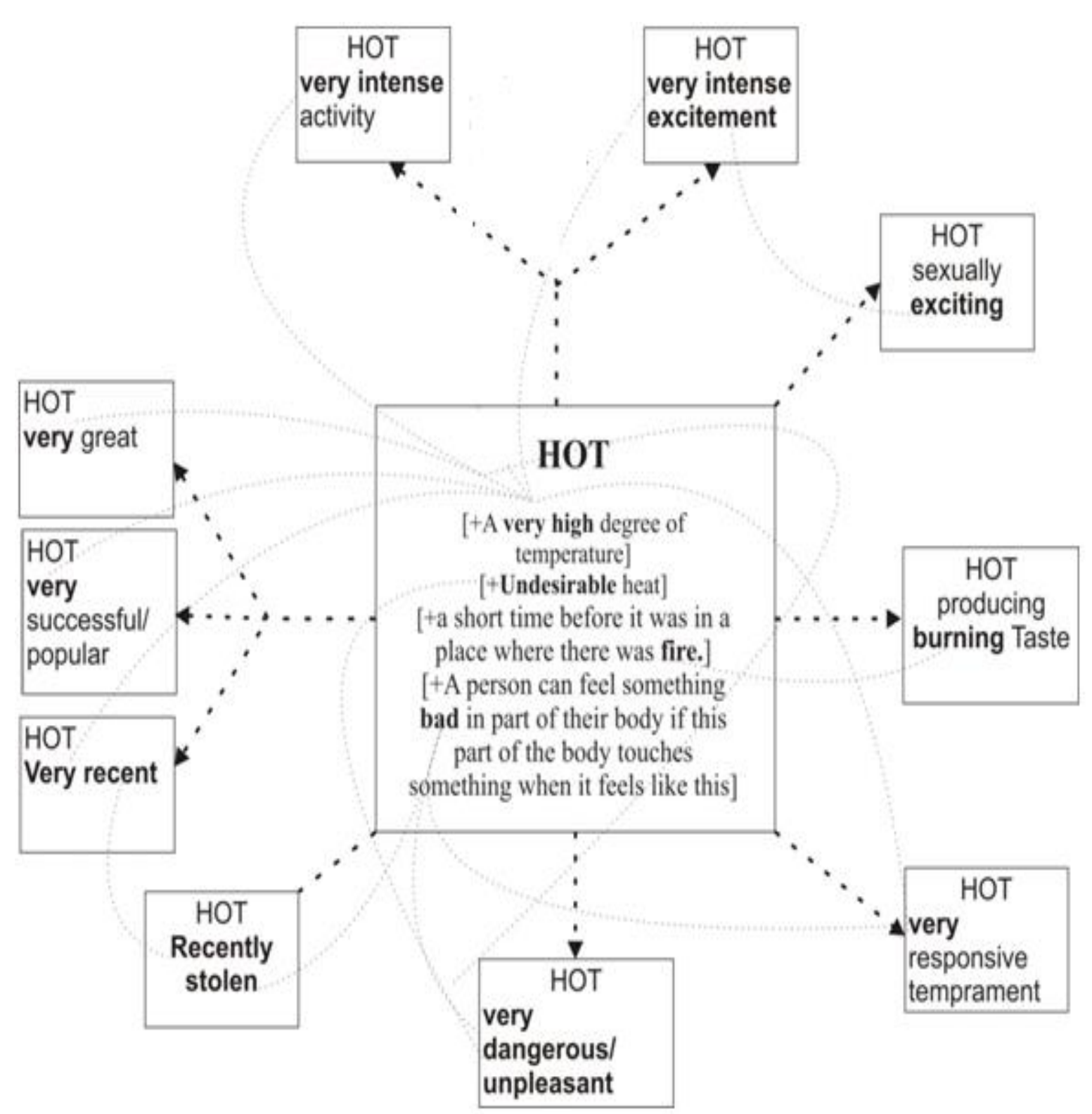

This picture shows that the extended senses of the word hot are still related to its prototypical meaning. The extension of those senses is mostly motivated by metaphors. The domain temparature is pervasive to express nontemperature entity because temperature is very basic human experience.

\section{CONCLUSION}

This research analyses a prototypical meaning and 10 extended senses of the word hot. The prototypical meaning of the word indicates a "very high degree of temperature". It is a scale used to describe temperature. The senses of the word hot are: (1) burning taste, (2) intense activity, (3) intense excitement, (4) great skill, (5) very successful, (6) very unpleasant, (7) newest or most recent (news), (8) recently stolen, (9) sexually excited or attractive, and (10) very responsive temperament. We have discussed how these senses are related to the central meaning of the word hot. The various senses of the word hot emerge because of metaphoric extension, in which the word hot is mostly used to describe a scale to measure other things. The relation of the senses enables us to draw the semantic network of the polysemy of the lexeme hot. 


\section{REFERENCES}

Cruse, Alan. (2000). Meaning In Language: An Introduction to Semantics and Pragmatics. Oxford: Oxford University Press

Evans, Vyvyan. and Melanie Green. (2006). Cognitive Linguistics: An Introduction. Edinburgh: Edinburgh University Press.

Finegan, E. (1992). Language: Its Structure and Use. London: Harcourt Brace Jovanovich

Falkum, Inggrid Lossius. (2011). The Semantics and Pragmatics of Polysemy: A Relevance-Theoretic Account. (Dissertation). London: University College London.

Kleparski, G. A. (2007). "Hot Pants, Cold Fish and Cool Customers". Seria Filologiczna.

Koptjevskaja-Tamm, Maria.___. "Kinds of Temperature Evaluation from A Lexical-Typological Perspective". www.temperature.ling.su.se/images/3/3d/MKT_temp_Lyon_1105_revis.doc accessed on 23 Mei 2012

Kovecses, Z. (2010). Metaphor: A Practical Introduction. $2^{\text {nd }}$ ed. Oxford: Oxford University Press.

Kridalaksana, H. (2011). Kamus Linguistik. Jakarta: Gramedia.

Ibarretxe-Antuñano, B. I. (1999). "Polysemy and Metaphor in Perception Verbs: A

Cross-Linguistic Study". (Dissertation). Edinburgh: University of Edinburgh.

Langacker, R. W. (2008). Cognitive Grammar. A Basic Introduction. Oxford: Oxford University Press.

Nida, A. E. (1975). Componential Analysis of Meaning, an Introduction to Semantic Structures. Paris : The Hague.

Ullmann, Stephen. (1977). Semantics, An Introduction to the Science of Meaning. Oxford:

Basil Blackwell.

Wierzbicka, Annal. (1992). Semantics, Culture, and Cognition: Universal Human Concepts in Culture Specific Configuration. London: Oxford University Press.

Wijaya, G. P. (2011). “Polisemi pada Leksem Head: Tinjauan Linguistik Kognitif”. (Thesis). Denpasar: Universitas Udayana. 